\title{
Low Back Pain Caused by lliopsoas Tendinopathy Treated with Ultrasound-Guided Local Injection of Anesthetic and Steroid: A Retrospective Study
}

This article was published in the following Dove Press journal: Journal of Pain Research

\section{Zhaochen Zhu (D) \\ Jieyuan Zhang \\ Jiagen Sheng \\ Changqing Zhang \\ Zongping Xie}

Department of Orthopedic Surgery, Shanghai Jiao Tong University Affiliated Sixth People's Hospital, Shanghai, People's Republic of China
Correspondence: Zongping Xie Shanghai Jiao Tong University Affiliated Sixth People's Hospital, 600 Yishan Road, Shanghai 200233, People's Republic of China

Tel $+86 \quad 18930173 \mid 55$

Fax+8621-64369l8I

Email x91034@qq.com
Background: Low back pain is a prevalent symptom that occurs in all age of people, whereas the pathogenesis is unknown. Iliopsoas tendinopathy is an increasingly recognized hip disorder that may contribute to low back pain. Our purpose is to evaluate the effect of ultrasound-guided local injection of anesthetic and steroid into the trigger point of iliopsoas tendon in treating low back pain caused by iliopsoas tendinopathy.

Materials and Methods: This retrospective study reviewed 45 patients diagnosed with iliopsoas tendinopathy treated by B-ultrasound guided injection of $2 \mathrm{~mL} 2 \%$ lidocaine and $1 \mathrm{~mL}(5 \mathrm{mg})$ triamcinolone acetonide into the trigger point of iliopsoas tendon from March 2016 to June 2016. Medical records were collected to analyze the clinical presentation. Numerical Rating Scale (NRS) measuring low back pain and Harris Hip score (HHS) measuring hip pain and function were administered to determine patient outcomes. Telephone follow-up was conducted, and the mean follow-up was 11 months.

Results: We observed that most patients with iliopsoas tendinopathy also complain about chronic low back pain except for groin pain. After injection of anesthetic and corticosteroid into the iliopsoas tendon, the NRS of patients with low back pain fell from $7.68 \pm 1.31$ to 2.58 \pm 1.16 immediately after the injection and $0.75 \pm 0.73$ at follow-up. The HHS improved from $43.02 \pm 16.81$ to $98.15 \pm 2.56$ at follow-up. Statistically significant difference $(P<0.001)$ was observed. All patients returned to their original level of function, and only five patients presented with mild low back pain at the follow-up.

Conclusion: Low back pain is a prevalent presentation for iliopsoas tendinopathy. Diagnosis of iliopsoas tendinopathy should be considered in patients with low back pain with tenderness over the iliopsoas tendon. Ultrasound-guided local injection of anesthetic and steroid lead to satisfactory effect in relieving low back and groin pain and improving joint function.

Keywords: low back pain, iliopsoas tendinopathy, spine, ultrasound

\section{Introduction}

Low back pain is a prevalent symptom that occur in all age groups. It is the number one cause of living with disability in 2017 according to the Global Burden of Disease Study (GBD). ${ }^{1}$ However, rarely can a specific cause of low back pain be identified, offering a diagnostic challenge for clinical doctors.

There is emerging evidence that low back pain coexists with hip disorder. ${ }^{2-4}$ Accordingly, patients with low back pain frequently have limited hip range of motion, and significant improvement of low back pain was observed after 
intervention for hip disease. ${ }^{5}$ A few researches have reported that psoas dysfunction contribute to low back pain, and the relationship between low back pain and psoas spasticity remains hypothesized. ${ }^{6-8}$ The iliopsoas muscle is regarded as the main flexor of the hip which is a confluence of the psoas and iliacus muscle. It originates from the lumbar vertebrae and pelvis, and lies beneath the inguinal ligament to inserts on the lesser trochanter. ${ }^{9}$ The iliopsoas tendon overlies directly the femoral head. When a tight iliopsoas tendon impinges on the femoral head and anterior hip capsule repetitively, resulting in chronic injury to the iliopsoas tendon, namely iliopsoas tendinopathy. Iliopsoas tendinopathy is a poorly recognized cause of groin pain. Overuse injury, acute trauma, and rheumatoid arthritis are the three main causes of iliopsoas tendinopathy. ${ }^{10}$ Currently, the diagnosis is largely made on the basis of the patient history, physical examination, and radiographs. Therapeutic injection of anesthetic and corticosteroid into the iliopsoas tendon sheath can help to confirm the diagnosis ${ }^{11,12}$ as well as alleviating the symptom of iliopsoas tendinopathy. ${ }^{13,14}$ We also observed that patients with iliopsoas tendinopathy often accompany low back pain.

In this study, our purpose is to (1) analyze the relationship between iliopsoas tendinopathy and low back pain, and (2) determine if ultrasound-guided local injection of anesthetic with corticosteroid into the trigger point of iliopsoas tendon can improve low back pain and function outcomes caused by iliopsoas tendinopathy.

\section{Materials and Methods}

We reviewed all patients with a diagnosis of iliopsoas tendinopathy and referred for an iliopsoas injection from March 2016 to June 2016 at our Hospital. The study protocol was approved by the Ethics Committee and all patients were informed about the study and gave their consent to be enrolled. The diagnosis of iliopsoas tendinopathy was based on a history of sustained groin pain, physical examination of focal tenderness over the iliopsoas tendon, and ruled out other hip pathologies. ${ }^{10,15,16}$ Confirmation of the diagnosis was determined by the immediate improvement of pain and focal tenderness over the iliopsoas tendon after injection. The patients complained of chronic anterior hip pain which is aggravated by activity, focal tenderness over the femoral triangle exaggerated on active straight leg raise with or without positive impingement test were included. Hip and lumber plain radiograph, CT, and MRI were conducted, and patients with the following conditions were excluded: malignant tumor, severe hepatic and renal dysfunction, rheumatoid diseases, recent (less than 6 months) lumber trauma, carried out lumber or hip surgery before or within follow-up, femoral acetabular impingement, labral tear, hip osteoarthritis, ankylosing spondylitis, and concomitant infection.

\section{Patients}

Fifty-one patients who met the inclusion criteria were reviewed consecutively. Six patients were lost to followup, so a total of 45 patients were enrolled. Of these patients, there were 26 males and 19 females with a mean age of 44.5 (range $=18-75$ years) (Table 1). All patients included underwent an ultrasound-guided iliopsoas injection by the same surgeon using the same treatment protocol. The ultrasound-guided injection was performed with the patient supine on the table with the transducer parallel to the iliopsoas tendon B-ultrasound showed that the iliopsoas tendon crossed normally over the bony acetabulum. The injection site was between the anterior inferior iliac spine and anterior superior iliac spine. The needle entry point was about $1 \mathrm{~cm}$ from the proximal edge of the transducer. Under the sonographic guidance, a combination of $2 \mathrm{~mL} 2 \%$ lidocaine and $1 \mathrm{~mL}$ (5 $\mathrm{mg}$ ) triamcinolone acetonide was injected into the iliopsoas tendon, where tenderness is the most obvious with a 22-gauge spinal needle (Figure 1). In order to identify the best location of injection, different loci of the tendon were acupunctured with the needle to elicit as many local twitch responses as possible. The trigger point was frequently found in the fascia of the iliopsoas tendon.

Table I Clinical Demographics of Patients Included

\begin{tabular}{|c|c|}
\hline \multicolumn{2}{|l|}{$n=45$} \\
\hline Gender, n (\%) & \\
\hline Male & $26(58 \%)$ \\
\hline Female & $19(42 \%)$ \\
\hline Age, years, mean $\pm S D$ (range) & $45 \pm 12(18-75)$ \\
\hline Body Mass Index, $\mathrm{kg} / \mathrm{m}^{2}$, mean $\pm \mathrm{SD}$ & $22.29 \pm 2.78$ \\
\hline Duration of pain, months, mean \pm SD (range) & $|3.0 \pm| \mid .83(3-36)$ \\
\hline Affected side, $\mathrm{n}(\%)$ & \\
\hline Left & 14 (3।\%) \\
\hline Right & $14(31 \%)$ \\
\hline Both & 17 (38\%) \\
\hline Follow-up time, months (range) & II (10-13) \\
\hline
\end{tabular}

Note: Demographic features in the 45 study patients. 

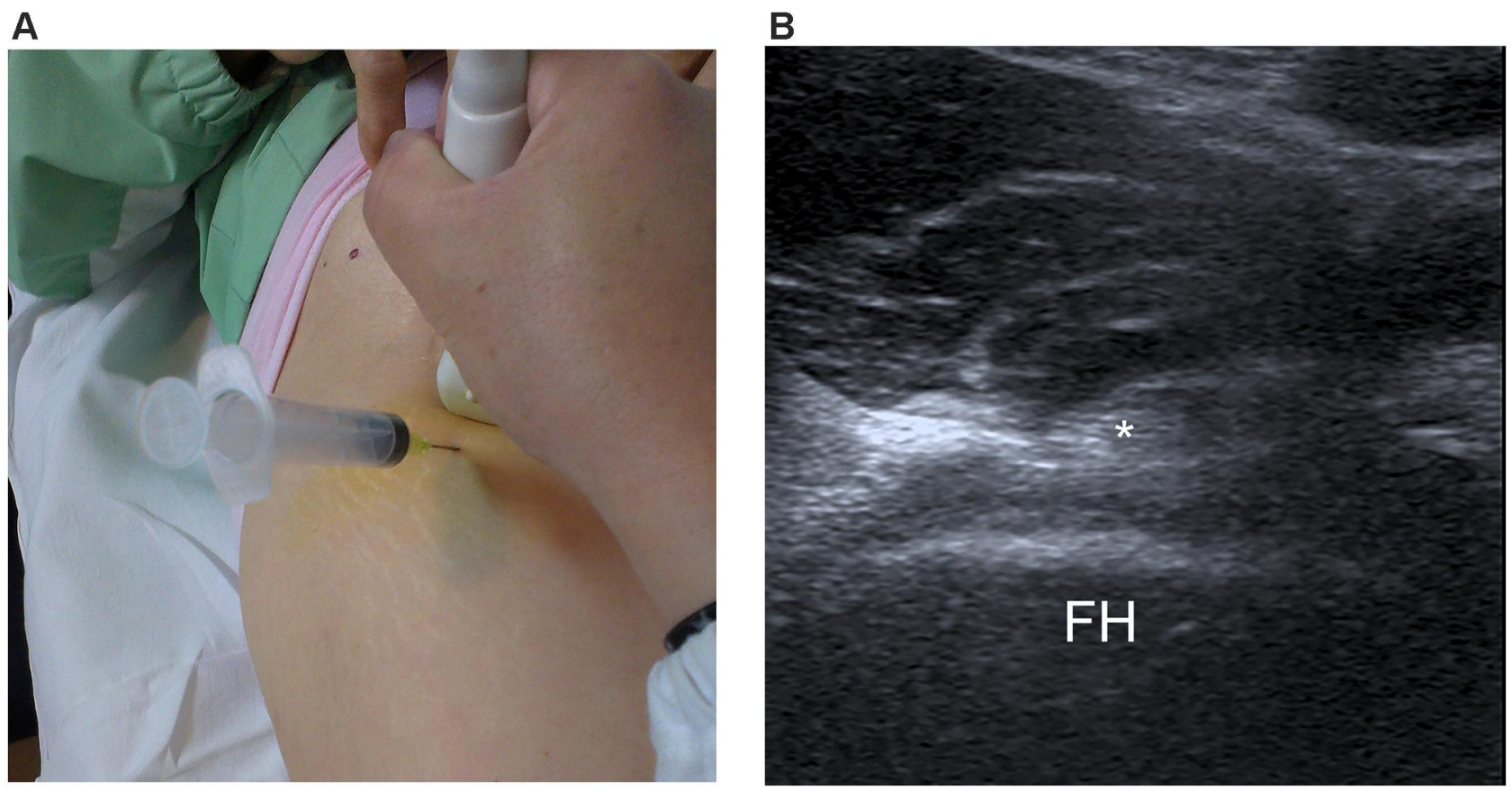

Figure I (A) The position of transducer and needle for iliopsoas injection. (B) Anterior view of the hip joint with iliopsoas tendon indicated by the asterisk. Abbreviation: $\mathrm{FH}$, femoral head.

The patients were asked to walk to determine if there was any difference from the original symptoms 10-15 minutes after the treatment. The diagnosis was determined by the immediate improvement of pain and focal tenderness over the iliopsoas tendon after injection. After the injection, all patients were asked to rest for 15 minutes in case of sideeffects and to keep the injection site dry for 5 hours. Clinical demographics of patients included

\section{Outcomes}

The primary outcomes analyzed were Numerical Rating Scale (NRS) and Harris Hip score (HHS). ${ }^{9}$ NRS score, which ranges from 0 (no pain) to 10 (worst pain possible), was used to evaluate pain in the low back area. The HHS is an outcome measurement of hip pain and hip function which ranges from $0-100$ (a total score of $<70$ is considered a poor result). Pretreatment and posttreatment HHS were compared with current published minimal clinically important difference (MCID) for HHS (delta $[\Delta]>10$ points). ${ }^{17}$ Secondary outcomes included complications (eg, infection, vascular injury).

We retrospectively reviewed the medical record for every patient and recorded their HHS and NRS before and after treatment, the clinical presentations were also acquired. We presented telephone follow-up an average of 11 months (range $=10-13$ months) after the treatment by one senior-level resident independent of the treating surgeon. We contacted all the 45 patients included by telephone at the follow-up.

\section{Statistical Methods}

Post-treatment NRS and HHS were compared with pretreatment values using Wilcoxon signed rank test and a two-tailed, paired Student's $t$-test separately. A $P$-value $<0.05$ was considered to be significant.

\section{Results}

In our study, 14 patients had left iliopsoas tendinopathy, 14 had right iliopsoas tendinopathy, and 17 had both iliopsoas tendinopathy. The mean BMI of these patients was 22.29 (Table 1). The chief complaint of these patients was chronic (more than 1 year) groin pain that increased with hip flexion and had difficulty wearing socks and was mostly accompanied by claudication. The mean duration of pain at their visit was 13 months (range $=3-36$ months). Forty-one of the 45 patients (91\%) complained of low back pain with groin pain, only four of them had pain only in the groin area. Five patients (11\%) complained mostly of pain in the buttock, which may radiate down to the thigh. Thirty-six patients $(80 \%)$ described the pain as paroxysmal, often induced by physical exercise or sedentariness. Half of the patients had difficulty turning 
Table 2 Clinical Outcomes in the Patients with Low Back Pain Under Injection

\begin{tabular}{|l|l|l|l|l|l|}
\hline & Before Treatment & Ten Minutes After Injection & $P$-value & Last Follow-Up & $P$-value \\
\hline Visual Analog scale & $7.68 \pm 1.31$ & $2.58 \pm 1.16$ & $<0.0001$ & $0.75 \pm 0.73$ & $<0.0001$ \\
Harris Hip score & $43.02 \pm 16.81$ & & & $98.15 \pm 2.56$ & $<0.000 \mathrm{I}$ \\
\hline
\end{tabular}

Note: Values are expressed as mean \pm SD (range) unless otherwise indicated.

over on the bed and 15 of them exaggerated when laying supine. Thirty-one patients $(69 \%)$ had limited hip flexion (have difficulty wearing socks or squatting). Eleven patients (24\%) complained of pain accompanied with snapping hip. Twenty-six patients (58\%) tried oral NSAIDs drugs to alleviate pain, nevertheless, all of them complained of temporary and limited effect. On physical examination, however, all 45 patients presented focal tenderness over the iliopsoas tendon, exaggerated with resistance, and accompanied with poor muscle strength. Impingement test were observed in eight cases. After the treatment, all 45 patients attended a telephone follow-up, up to the 1-year post-treatment assessment.

In those 41 patients with low back pain. The NRS before treatment was $7.68 \pm 1.31$. This fell to $2.58 \pm 1.16$ 10 minutes after the injection. At 1-year post-treatment, the NRS was $0.75 \pm 0.73$. Forty of the 41 patients achieved greater than or equal to $50 \%$ NRS reduction from base line. A statistically significant difference $(P<0.001)$ was observed. The pre-treatment Harris hip score was 43.02 \pm 16.81 . It improved to $98.15 \pm 2.56$ at 1 year after the injection, significantly improved compared with pretreatment value $(P<0.001)$. All the patients included reached MCID (Table 2).

Six patients (13\%) complained of dizziness after the injection due to anesthesia and all recovered after resting for 10-20 minutes. No patient had infection, vascular injury, or any major complication. Most patients had a single injection, five patients (three with low back pain and two without) were given a second injection 1 month after the first injection. Although alleviated focal tenderness was observed immediately after the first injection, these five patients still had severe groin with or without low back pain and focal tenderness over the iliopsoas tendon, exaggerated when resistance 1 month after the first injection. According to their symptoms and lack of signs for other possible diagnosis, iliopsoas tendinopathy is still the first consideration, so the second injection was given. Ultimately, all patients returned to their original level of function after the injection, only five patients still presented with mild low back pain (NRS range $=2-3$ ) at last follow-up.

\section{Discussion}

Although low back pain caused by lumbar structure disorder remain popular in some settings, the usefulness of these diagnosis in guiding treatment remains unclear. ${ }^{21}$ Among asymptomatic individuals, imaging findings of spine degeneration (disc bulge, disc protrusion) is prevalent. ${ }^{22}$ What is more, the rate of spontaneous regression was found to be $96 \%$ for disc sequestration, $70 \%$ for disc extrusion, $41 \%$ for disc protrusion, and $13 \%$ for disc bulging. ${ }^{23}$ Thus, identifying the pathoanatomical basis of low back pain is in urgent need to open up new approaches for people with disabling low back pain worldwide.

Disorders of hip and lumbar have overlapping presentations and symptoms. Prather et $\mathrm{al}^{24}$ found that positive hip physical examination is prevalent in patients with low back pain, patients with low back pain, and positive hip examination findings have more pain and worse function compared with patients without hip examination findings. It is estimated that about $60.4 \%$ patients with hip osteoarthritis also complain of low back pain, and after total hip arthroplasty, significant improvement of low back pain can be observed 1-year postoperative. ${ }^{25}$ According to a systematic review of Redmond et al, ${ }^{5}$ patients with low back pain frequently accompany limited hip range of motion, and these patients routinely improve after surgical intervention for hip diseases. Hip diseases may closely relate with low back pain, but by what means are they related is still unknown. The iliopsoas musculotendinous unit is a powerful hip flexor which has important function in femoral external rotation and with lateral bending, flexion, and stabilizing the spine in the frontal plane. ${ }^{26,27}$ It originates from the outer surfaces of the vertebral bodies of T12-L5 and inserts on the lesser trochanter of the femur (Figure 2). We hypothesize that the pathology of the iliopsoas musculotendinous unit may contribute to low back pain caused by hip disorders.

Iliopsoas tendinopathy is closely related with the repetitive pathologic movement of the tendon. In this study, we found that low back pain is a common symptom for iliopsoas tendinopathy and could be significantly relieved after local injection of anesthetic and steroid into the trigger point of 


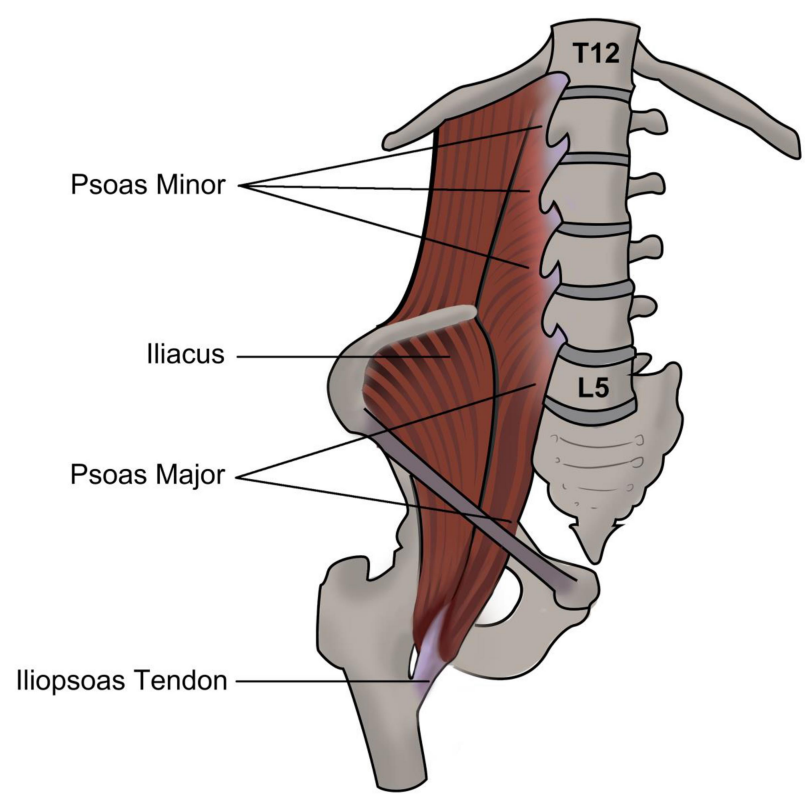

Figure 2 The anatomic relation of iliopsoas and the spine.

iliopsoas tendon, indicating iliopsoas tendinopathy is a plausible source of low back pain. Altogether, we believe that the iliopsoas tendon is a structure closely related with the generation of low back pain. But further investigation is needed to further confirm the relation between iliopsoas tendinopathy and low back pain. Besides, why does iliopsoas tendinopathy generate low back pain and how do intraarticular pathologies correlate with iliopsoas tendinopathy and contribute to low back pain? This is still unknown.

To our knowledge, this study is the first study to report low back pain as a major presentation for iliopsoas tendinopathy, and investigate the clinical effect of local injection of corticosteroid into the iliopsoas tendon on low back pain. Our results showed that ultrasound-guided injection of anesthetic and steroid into the trigger point of the iliopsoas tendon can improve low back and groin pain significantly for patients with iliopsoas tendinopathy. Significant mid-term outcome was also observed in our study. In total, 84\% (38 of 45 patients) presented absolute pain relief and an improved HHS at follow-up. In patients with low back pain and/or groin pain and local tenderness over the iliopsoas tendon, iliopsoas tendinopathy should be considered. CT and MRI can be helpful in excluding other diagnoses, including osteoarthritis and femoral acetabular impingement. Local injection of anesthetic and steroid can be applied as both therapy and a way of confirming the diagnosis.

Consistent with previous research, our result also demonstrated that local injection of anesthetic and steroid has a therapeutic effect on iliopsoas pathology at mid-term followup. Han et $\mathrm{al}^{28}$ demonstrated US-guided iliopsoas corticosteroid injection improved outcome at 6-week follow-up. In patients with painful snapping hip, injection can be beneficial, 16 of 18 patients in the study had a good response at an average of 4 months. ${ }^{29}$ Adler et al ${ }^{13}$ performed sonographyguided peritendinous injection for the presumed diagnosis of iliopsoas tendinosis, $44 \%$ of these patients had continued relief at 1 year. Agten et $\mathrm{al}^{14}$ reported an improvement at 1 month of the patients with iliopsoas tendinopathy after fluoroscopyguided iliopsoas bursa injection of triamcinolone and lidocaine. For patients with iliopsoas impingement after total hip arthroplasty, non-operative management is reported to lead to groin pain resolution in $50 \%$ of patients. ${ }^{30}$ Nevertheless, a systematic review showed that non-surgical treatment including injection was only successful in 39\% of patients with iliopsoas impingement after total hip arthroplasty. ${ }^{31}$

Although we demonstrated a promising therapeutic effect of local injection on low back pain caused by iliopsoas tendinopathy, however, there are several limitations of our study. We included a relatively small number of patients with iliopsoas tendinopathy, and long-term follow-up is needed to further confirm our results, and short-term follow up at 2-weeks and 3 months was not done in our research. Additionally, we had no control group for comparison, and we present our study in a single center. We will further amplify the sample size and put randomized controlled trials into practice to confirm our study. Another limitation of our study is that the use of NRS and HHS to assess the outcome are subjective, the sense of pain can vary from person to person.

\section{Conclusions}

In conclusion, iliopsoas tendinopathy closely correlates with low back pain. Most patients with iliopsoas tendinopathy complain of low back pain. The diagnosis of iliopsoas tendinopathy should also be considered in patients with low back pain and local tenderness over the iliopsoas tendon. Ultrasoundguided local injection of anesthetic and steroid into the trigger point of the iliopsoas tendon is easy to conduct and can significantly improve low back pain and joint function. It can be used as a routine treatment for iliopsoas tendinopathy.

\section{Ethics Approval and Consent to Participate}

All procedures performed in studies involving human participants were in accordance with the ethical standards of the Ethics Committee of Shanghai Sixth People's Hospital 
(2019-KY-019 (K)) and with the 1964 Helsinki declaration and its later amendments or comparable ethical standards. All the figures included are original.

\section{Funding}

This work was supported by funds from the National Natural Science Foundation of China (Grant Nos: 81572120).

\section{Disclosure}

The authors declare that they have no conflicts of interest.

\section{References}

1. Lancet T. GBD 2017: a fragile world. Lancet. 2018;392(10159):1683. doi:10.1016/S0140-6736(18)32858-7

2. Clohisy JC, Knaus ER, Hunt DM, Lesher JM, Harris-Hayes M, Prather $\mathrm{H}$. Clinical presentation of patients with symptomatic anterior hip impingement. Clin Orthop Relat Res. 2009;467(3):638-644. doi:10.1007/s11999-008-0680-y

3. Burnett RS, Della Rocca GJ, Prather H, Curry M, Maloney WJ, Clohisy JC. Clinical presentation of patients with tears of the acetabular labrum. J Bone Joint Surg Am. 2006;88(7):1448-1457. doi:10.2106/00004623-200607000-00004

4. Nunley RM, Prather H, Hunt D, Schoenecker PL, Clohisy JC. Clinical presentation of symptomatic acetabular dysplasia in skeletally mature patients. J Bone Joint Surg Am. 2011;93(Suppl 2):17-21. doi:10.2106/JBJS.J.01735

5. Redmond JM, Gupta A, Hammarstedt JE, Stake CE, Domb BG. The hip-spine syndrome: how does back pain impact the indications and outcomes of hip arthroscopy? Arthroscopy. 2014;30(7):872-881. doi:10.1016/j.arthro.2014.02.033

6. Siccardi MA, Valle C. Anatomy, bony pelvis and lower limb, psoas major. In: StatPearls. Treasure Island (FL): StatPearls Publishing StatPearls Publishing LLC; 2019. Available from: http://www.ncbi. nlm.nih.gov/books/NBK535418/. Accessed November 13, 2020.

7. Tufo A, Desai GJ, Cox WJ. Psoas syndrome: a frequently missed diagnosis. $J$ Am Osteopath Assoc. 2012;112(8):522-528. doi:10.7556/jaoa.2012.112.8.522

8. Marrè-Brunenghi G, Camoriano R, Valle $\mathrm{M}$, Boero $\mathrm{S}$. The psoas muscle as cause of low back pain in infantile cerebral palsy. $J$ Orthop Traumatol. 2008;9(1):43-47. doi:10.1007/s10195-008-0104-5

9. Blomberg J, Zellner B, Keene J. Cross-sectional analysis of iliopsoas muscle-tendon units at the sites of arthroscopic tenotomies: an anatomic study. Am J Sports Med. 2011;39(1_suppl):58S-63S. doi:10.1177/0363546511412162

10. Johnston CAM, Wiley JP, Lindsay DM, Wiseman DA. Iliopsoas bursitis and tendinitis. A review. Sports Med. 1998;25(4):271-283. doi:10.2165/00007256-199825040-00005

11. Wank R, Miller T, Shapiro J. Sonographically guided injection of anesthetic for iliopsoas tendinopathy after total hip arthroplasty. J Clin Ultrasound. 2004;32(7):354-357. doi:10.1002/jcu.20043

12. Nunley R, Wilson J, Gilula L, Clohisy J, Barrack R, Maloney W. Iliopsoas bursa injections can be beneficial for pain after total hip arthroplasty. Clin Orthop Relat Res. 2010;468(2):519-526. doi:10.1007/s11999-009-1141-y
13. Adler RS, Buly R, Ambrose R, Sculco T. Diagnostic and therapeutic use of sonography-guided iliopsoas peritendinous injections. AJR Am $J$ Roentgenol. 2005;185(4):940-943. doi:10.2214/AJR.04.1207

14. Agten CA, Rosskopf AB, Zingg PO, Peterson CK, Pfirmann CWA. Outcomes after fluoroscopy-guided iliopsoas bursa injection for suspected iliopsoas tendinopathy. Eur Radiol. 2015;25(3):865-871. doi:10.1007/s00330-014-3453-x

15. Cascio BM, King D, Yen YM. Psoas impingement causing labrum tear: a series from three tertiary hip arthroscopy centers. $J$ La State Med Soc. 2013;165(2):88-93.

16. Domb B, Shindle M, McArthur B, Voos J, Magennis E, Kelly B. Iliopsoas impingement: a newly identified cause of labral pathology in the hip. HSS J. 2011;7(2):145-150. doi:10.1007/s11420-011-9198-z

17. Levy D, Kuhns B, Chahal J, Philippon M, Kelly B, Nho S. Hip arthroscopy outcomes with respect to patient acceptable symptomatic state and minimal clinically important difference. Arthroscopy. 2016;32(9):1877-1886. doi:10.1016/j.arthro.2016.05.014

18. Maher C, Underwood M, Buchbinder R. Non-specific low back pain. Lancet. 2017;389(10070):736-747. doi:10.1016/S0140-6736(16) 30970-9

19. Buchbinder R, Hartvigsen J, Cherkin D, et al. What low back pain is and why we need to pay attention. Lancet. 2018;391:10137.

20. Koes BW, Van Tulder M, Thomas S. Diagnosis and treatment of low back pain. BMJ. 2006;332(7555):1430-1434. doi:10.1136/bmj.332.7555.1430

21. Hancock MJ, Maher CG, Latimer J, et al. Systematic review of tests to identify the disc, SIJ or facet joint as the source of low back pain. Eur Spine J. 2007;16(10):1539-1550. doi:10.1007/s00586-007-0391-1

22. Brinjikji W, Luetmer PH, Comstock B, et al. Systematic literature review of imaging features of spinal degeneration in asymptomatic populations. Am J Neuroradiol. 2015;36(4):811-816. doi:10.3174/ajnr.A4173

23. Chiu -C-C, Chuang T-Y, Chang K-H, Wu C-H, Lin P-W, Hsu W-Y. The probability of spontaneous regression of lumbar herniated disc: a systematic review. Clin Rehabil. 2015;29(2):184-195. doi:10.1177/ 0269215514540919

24. Prather H, Cheng A, Steger-May K, Maheshwari V, Van Dillen L. Hip and lumbar spine physical examination findings in people presenting with low back pain, with or without lower extremity pain. $J$ Orthop Sports Phys Ther. 2017;47(3):163-172. doi:10.2519/jospt.2017.6567

25. Staibano P, Winemaker M, Petruccelli D, de Beer J. Total joint arthroplasty and preoperative low back pain. $J$ Arthroplasty. 2014;29(5):867-871. doi:10.1016/j.arth.2013.10.001

26. Mann RA, Moran GT, Dougherty SE. Comparative electromyography of the lower extremity in jogging, running, and sprinting. $A m$ J Sports Med. 1986;14(6):501-510.

27. Andersson E, Oddsson L, Grundström H, Thorstensson A. The role of the psoas and iliacus muscles for stability and movement of the lumbar spine, pelvis and hip. Scand J Med Sci Sports. 1995;5 (1):10-16. doi:10.1111/j.1600-0838.1995.tb00004.x

28. Han JS, Sugimoto D, McKee-Proctor MH, Stracciolini A, d'Hemecourt PA. Short-term effect of ultrasound-guided iliopsoas peritendinous corticosteroid injection. J Ultrasound Med. 2019;38 (6):1527-1536. doi:10.1002/jum.14841

29. Blankenbaker DG, Smet AAD, Keene JS. Sonography of the iliopsoas tendon and injection of the iliopsoas bursa for diagnosis and management of the painful snapping hip. Skeletal Radiol. 2006;35 (8):565-571. doi:10.1007/s00256-006-0084-6

30. Chalmers BP, Sculco PK, Sierra RJ, Trousdale RT, Berry DJ. Iliopsoas impingement after primary total hip arthroplasty: operative and nonoperative treatment outcomes. JBJS. 2017;99(7):557. doi:10.2106/JBJS.16.00244

31. Lachiewicz PF, Kauk JR. Anterior iliopsoas impingement and tendinitis after total hip arthroplasty. J Am Acad Orthop Surg. 2009;17 (6):337-344. doi:10.5435/00124635-200906000-00002 


\section{Publish your work in this journal}

The Journal of Pain Research is an international, peer reviewed, open access, online journal that welcomes laboratory and clinical findings in the fields of pain research and the prevention and management of pain. Original research, reviews, symposium reports, hypothesis formation and commentaries are all considered for publication. The manuscript

Submit your manuscript here: https://www.dovepress.com/journal-of-pain-research-journa management system is completely online and includes a very quick and fair peer-review system, which is all easy to use. Visit http:// www.dovepress.com/testimonials.php to read real quotes from published authors. 